\title{
Modulation of acetate utilization in Komagataella phaffii by metabolic engineering of tolerance and metabolism
}

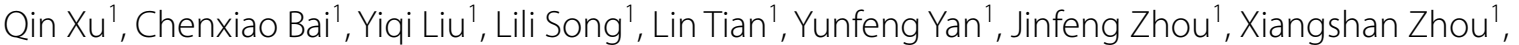 \\ Yuanxing Zhang ${ }^{1,2}$ and Menghao Cai ${ }^{*}$ (D)
}

\begin{abstract}
Background: Acetate, an economical industrial chemical, which is also the precursor of acetyl-CoA, could serve as an alternative substrate for biomanufacturing. This nontraditional substrate can be widely produced from syngas via hydrolysis or pyrolysis of the cellulosic biomass, chemical or microbial catalysis, anaerobic fermentation in treated wastewater, etc. However, the toxicity of acetate to microorganisms has held back its utilization, especially for the eukaryotes that are good hosts for production of complicated pharmaceuticals or chemicals. This study seeks to improve acetate utilization in a widely used yeast host, Komagataella phaffii (previously Pichia pastoris), by metabolic engineering of acetate tolerance, transport, and metabolism.
\end{abstract}

Results: A kinase-deficient library of K. phaffii was firstly used to screen acetate-resistant kinases. The HRK1 knockout strain was sensitive to acetate and overexpression of this gene improved acetate tolerance and cell growth of the strain. Also, overexpression of HRK1 caused a 55\% productivity improvement of acetyl-CoA-dependent 6-methylsalicylic acid (6-MSA). However, activation of Hrk1 on membrane H(+)-ATPase Pma1 seemed not to work in the engineered strain. Acetate transporter gene SCFPS ${ }^{*}$ was further overexpressed, despite of not improving 6-MSA biosynthesis. To enhance acetate metabolism, acetyl-CoA synthesizing related genes, yeast PpACS1, SCACS1*, and E. coli ackA pta were overexpressed separately. Introduction of PpACS1 and SCACS1* each increased biosynthesis of 6-MSA by approximately 20\% on $20 \mathrm{mM}$ acetate. Finally, co-overexpression of HRK1 and SCACS1* improved 6-MSA productivity by $51 \%$ on $20 \mathrm{mM}$ acetate, despite that a low expression level of HRK1 happened when genes were expressed under the same promoter.

Conclusions: HRK1 screened by K. phaffii kinase-deficient library played an important role in acetate tolerance and was proved to profit the biosynthesis of acetyl-CoA-derived chemicals. It could be a potential target for metabolic engineering of acetate utilization in other eukaryotic hosts as well. A combined strategy of introducing genes for acetate tolerance and metabolism further improved biosynthesis of acetyl-CoA derived reporter compound in $K$. phaffii. This makes it a good choice for acetyl-CoA-derived chemicals with acetate as substrate or precursor in K. phaffii, which would also extend the use of this chassis host.

Keywords: Komagataella phaffii, Acetate utilization, Acetyl-CoA, Kinase screening, Metabolic engineering

\section{Background}

As promising substrates for industrial biomanufacturing, nontraditional carbon sources, such as acetate, methane,

\footnotetext{
*Correspondence: cmh022199@ecust.edu.cn

1 State Key Laboratory of Bioreactor Engineering, East China University

of Science and Technology, Shanghai 200237, China

Full list of author information is available at the end of the article
}

methanol, and syngas, have attracted great attention recently. Acetate $\left(\mathrm{C}_{2} \mathrm{H}_{4} \mathrm{O}_{2}\right)$ is one of the simple weak acids, which can be widely produced from syngas via chemical [1] or microbial [2] catalysis or generated from hydrolysis or pyrolysis of the cellulosic biomass [3]. Acetate is also a product of anaerobic fermentation in treated wastewater [4]. 
Some microorganisms can utilize acetate as a substrate supporting cell growth and metabolism, including the oleaginous yeast Cryptococcus curvatus $[5,6]$, Escherichia coli [7, 8], and Corynebacterium glutamicum [9]. Acetate can be directly converted into acetyl-CoA, which is catalyzed by cytosolic acetyl-CoA synthetase in eukaryotes such as yeast [10] and by acetate kinase/phosphotransacetylase in prokaryotes like C. glutamicum [9] and E. coli [11]. Importantly, acetyl-CoA is a key intermediate of metabolic process in the tricarboxylic acid (TCA) cycle, glyoxylate cycle, and fatty acid synthesis. It also acts as a precursor for many industrially interesting biotechnological products, such as polyketides [12], isoprenoids [13], and lipids [5]. In eukaryotes, acetyl-CoA is compartmentalized in different organelles, which usually limits the conversion efficiency of acetyl-CoA into its derived products [14]. Therefore, acetate may be a promising substrate for enrichment of cytosolic acetyl-CoA and its derived products.

Recently, examples of value-added products derived from acetate by either engineered or natural microbial hosts have been well reported from prokaryotes [7, 8]. An E. coli strain with co-overexpression of acs (acetyl-CoA synthase gene) and tes A (acyl-ACP thioesterase gene) and deletion of fadE (acyl-CoA dehydrogenase gene) produced about $1 \mathrm{~g} / \mathrm{L}$ fatty acids from acetate [8]. The recombinant strain even produced impressive quantities of fatty acids from acetate-rich liquid wastes via dilute acid hydrolysis of lignocellulosic biomass and anaerobicdigested sewage sludge [8]. In another case, succinate production using acetate as the sole carbon source was achieved by modifying the TCA cycle, gluconeogenesis pathway, and glyoxylate shunt in an engineered $E$. coli strain, in which the genes $s d h A B$ (encoding succinate dehydrogenase), $i c l R$ (encoding isocitrate lyase regulator), and maeB (encoding malic enzyme) were deleted and $g l t A$ (encoding citrate synthase) was overexpressed [7]. Some oleaginous yeasts can well utilize acetate, i.e., C. curvatus accumulated lipids even up to $73.4 \%$ of its dry biomass weight on acetate and glucose [5]. However, acetate easily causes strong antimicrobial effects on the widely used yeast hosts of Saccharomyces cerevisiae [15] and Komagataella phaffii (previously Pichia pastoris) (this study), despite of limited reports regarding metabolic engineering on acetate metabolism in these species [16].

Acetate usually shows antimicrobial action at low $\mathrm{pH}$ $(<\mathrm{pKa}$ of 4.76$)$ in the undissociated state [15]. In the presence of glucose, undissociated acetate enters cells primarily through the Fps1 aquaglyceroporin channel by facilitated diffusion and dissociates into acetate and proton because of the neutral $\mathrm{pH}$ of cytosol in yeast [17]. Acidification of cytoplasm occurs with the accumulation of protons, resulting in the inhibition of important metabolic processes [18] and even programmed cell death [19]. To overcome the stress caused by acetate, Hog1 MAPK is transiently activated in yeast and then phosphorylates Fps1, resulting in Fps1 becoming ubiquitinated, endocytosed, and finally degraded in the vacuole [17]. The degradation of Fps1 is one approach to acetate adaptation in yeast like $S$. cerevisiae. Acetate also leads to activation of the $\mathrm{H}(+)$-ATPase Pma1 located on yeast plasma membrane, which functions to pump protons dissociated by acetate molecules out of cells [20]. Pma1 is crucial for yeast adaptation to acetate, creating an electrochemical proton gradient that is essential for the uptake of nutrients and regulates intracellular $\mathrm{pH}$ balance [21, 22]. Moreover, transcription factor Haa1 is essential for rapid adaptation of yeast to acetate, and directly or indirectly regulates approximately $80 \%$ of acetate-induced gene expression [23, 24]. Accordingly, the potential for cell death in response to acetate must be considered when developing acetate as substrate.

Komagataella phaffii is a versatile and powerful expression host, supporting good expression and bioactivity levels of heterologous proteins [25]. It has been researched for years with mature genetic operation and commercialized vectors and strains [26]. In recent studies, $K$. phaffii has been defined as a good host for biosynthesis of pharmaceutical and chemical molecules derived from acetyl-CoA [27, 28]. Therefore, K. phaffii may hold good potential for use in biomanufacturing that converts acetate into a variety of acetyl-CoA-derived [10] and value-added compounds beyond the recombinant proteins.

However, this study finds that $K$. phaffii is quite sensitive to acetate (highly inhibited by acetate over $40 \mathrm{mM}$, Additional file 1: Fig. S1), which even shows increased sensitivity on comparing with S. cerevisiae [17]. We then aim to engineer $K$. phaffii to improve bio-utilization of acetate by metabolic engineering on acetate tolerance, transport and metabolism. As acetate typically causes kinase-related programmed cell death [29, 30], acetateresistant kinases were screened from a previously constructed $K$. phaffii kinase deletion library [31] and used for construction of acetate-tolerant strains. The reported genes associated with acetate transport [17] and metabolism [32] were overexpressed and their functions in $K$. phaffi $i$ were tested. By this means, we dedicate to develop $K$. phaffii strains that can efficiently utilize acetate for production of pharmaceuticals and chemicals.

\section{Results and discussion}

Screening of acetate tolerance-related genes in K. phaffii kinase deletion library

Toxic levels of acetate may induce programmed cell death (PCD) in yeast, but how the stress signals transmit to 
cytosol is still not clear yet [29]. Kinases play an important role in cellular signal transduction and are commonly involved in the PCD process [29]. Some kinases, like Hog1, function in acetate transport [29]. There are a total of 152 annotated kinases throughout the genome of $K$. phaffii GS115 [33]. We previously constructed a kinase deletion library consisting of 92 knockout strains of non-essential kinases to screen targets correlated with regulation of methanol metabolism in the methylotrophic yeast $K$. phaffii [31]. Seeing that kinases function in various pathways of cellular signal transduction, we then proceeded to use this kinase deletion library to screen acetate-resistant kinases in this work. Three kinase-knockout strains growing normally without acetate but showing increased sensitivity to acetate (Fig. 1) were screened after examining cell growth on YPD plates supplemented with 0,30 and $40 \mathrm{mM}$ acetate (Additional file 1: Fig. S2).

Details of annotation and homologs of the screened kinases are summarized in Table 1 . The kinase deleted in PAS_chr3_1091 strain was implicated in activation of the plasma membrane $\mathrm{H}(+)$-ATPase Pma1. Its homolog in S. cerevisiae encoded a protein kinase belonging to a family dedicated to the regulation of plasma membrane transporters [30], and it was reported to be possibly involved in the reduction of intracellular acetate concentration [24]. Therefore, PAS_chr3_1091 is one of the likely targets for acetate

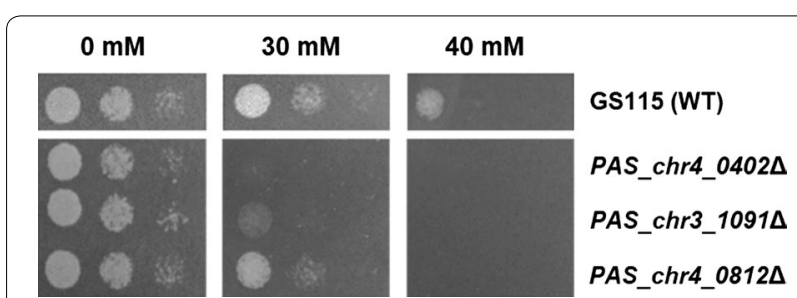

Fig. 1 Cell growth of the acetate sensitive knockouts. K. phaffii phenotypes of wild-type GS115 (WT), $\triangle$ PAS_chr3_1091 (DHRK1), $\triangle P A S \_c h r 4 \_0402$, and $\triangle P A S \_c h r 4$ 0812 are shown. Cells were spotted on YPD agar plates ( $\mathrm{pH} 4.5$ ) with acetate of 0,30 and $40 \mathrm{mM}$ at three concentrations $\left(\mathrm{OD}_{600}=0.1,0.01\right.$ and 0.001$)$. These strains were selected from among the 92 kinase gene knockouts (Additional file 1: Fig. S2) tolerance modification. The PAS_chr4_0402 is annotated as beta regulatory subunit of casein kinase 2, which has a homolog, Ckb1, in S. cerevisiae and is related to cell survival [34]. The PAS_chr4_0812 is annotated as protein serine/threonine/tyrosine kinase, and its homologous gene in S. cerevisiae encodes Mck1, playing roles in chromosome segregation and in regulating entry into meiosis $[35,36]$. There were also some other knockouts displaying mild sensitivity to high acetate concentrations (Additional file 1: Fig. S2), indicating the complicated response and adaptation of $K$. phaffii cells to acetate stress. As is annotated, the PAS chr3_1091 was closely related to acetate-related physiological process [20-22] and was homologous to HRK1 in the model yeast of $S$. cerevisiae. Therefore, we identified PAS_chr3_1091as HRK1 and used it as the target for modifying acetate tolerance.

Besides, deficiency of some kinases caused severe growth defects even in YPD plates without acetate (Additional file 1: Fig. S2). For instance, the PAS_chr21_0162 encodes a histidine kinase osmosensor and has a homolog, Sln1, involved in the Hog1 MAP kinase cascade in S. cerevisiae [37]. The PAS_chr2-1_0402 is annotated as alpha subunit of heterooctameric phosphofructokinase involved in glycolysis, which has a homolog of Pfk1 in S. cerevisiae. The PAS_chr3_0042 encodes a myristoylated serine/threonine protein kinase involved in vacuolar protein sorting, and its homologous gene encodes Vps15, which is involved in vesicular protein trafficking in S. cerevisiae [38]. These kinases are closely related with primary metabolism or global physiological processes, confirming their putative functions as annotated.

\section{Loss of $H R K 1$ influences acetate tolerance and cell growth of $K$. phaffii}

To confirm the role of Hrk1 in acetate tolerance, growth of $K$. phaffii GS115 (wild type) and HRK1 knockout strain was measured under gradient of acetate concentrations (Additional file 1: Fig. S3). Deletion of HRK1 caused cell growth of $K$. phaffii to be more sensitive to elevated acetate concentrations ( 30 and $40 \mathrm{mM}$ ). Complementation and overexpression of HRK1 were then conducted (Additional file 1: Fig. S4). As shown in Fig. 2a,

Table 1 Kinases related to acetate tolerance screened from $K$. phaffii kinase deletion library [31]

\begin{tabular}{lll}
\hline Coding gene & Annotation & Homolog in S. cerevisiae \\
\hline PAS_chr3_1091 & Protein kinase implicated in activation of the plasma membrane H(+)- & Putative serine/threonine protein kinase Hrk1 \\
& ATPase Pma1p & Casein kinase 2 regulatory subunit Ckb1 \\
PAS_chr4_0402 & Beta regulatory subunit of casein kinase 2, a Ser/Thr protein kinase & Serine/threonine/tyrosine protein kinase Mck1 \\
PAS_chr4_0812 & Protein serine/threonine/tyrosine (dual-specificity) kinase &
\end{tabular}


complementation of $H R K 1$ in $\Delta h r k 1$ largely recovered its growth in the presence of $30 \mathrm{mM}$ acetate. Overexpression of HRK1 in the wild type further improved cell growth on medium with $30 \mathrm{mM}$ acetate. These results indicated that the kinase encoded by $H R K 1$ played a critical role in acetate tolerance in $K$. phaffii.

As Hrk1 was implicated in activation of the plasma membrane $\mathrm{H}(+)$-ATPase Pma1 [30], the impact of Hrk1 on Pmal was then analyzed. As previously reported, Pma1 is a membrane protein in S. cerevisiae [39]. Thus, subcellular localization of $K$. phaffii Pma1 was firstly confirmed through a fusion protein of Pma1-green fluorescent protein (GFP). Fluorescence results demonstrated that Pma1 is localized in the membrane in $K$. phaffii (Additional file 1: Fig. S5). Moreover, Student's $t$ test analysis $(P<0.05)$ indicated that extracellular $\mathrm{pH}$ of recombinant strains of GS-PMA1 and GS-HRK1/PMA1 probably differed from that of GS115 and GS-HRK1 at 46 and $58 \mathrm{~h}$ (Fig. 2b). Western blot results showed both HRK1 and PMA1 were successfully expressed (Additional file 1: Fig. S4). The results indicated that variation in the extracellular $\mathrm{pH}$ was attributable to Pma1 overexpression. In contrast, overexpression of HRK1 did not affect extracellular $\mathrm{pH}$. However, overexpression of either HRK1 or PMA1 enhanced acetate tolerance and cell growth of $K$. phaffii (Fig. 2c). It has been reported that Pma1 is the most abundant protein in the plasma membrane of $S$. cerevisiae and mutation of its phosphorylation sites altered overall ATPase activity in $S$. cerevisiae [40, 41]. Thus, the total ATPase activity was assayed in the WT and $\Delta h r k 1$ cultivated in $1 \%$ glucose, $30 \mathrm{mM}$ acetate or their mixture, and the results are presented in Fig. 2d. The ATPase activity of both strains showed no significant difference under the three conditions. Thus, the activation effect of Hrk1 on Pma1 seemed not to work in $K$. phaffii, despite Hrk1 and Pma1 both exhibiting specific functions in regulation of intracellular acetate concentration. However, Hrk1 indeed regulated Pma1 in response to glucose in S. cerevisiae [37]. Thus, the results leave open the question of the molecular mechanism of a Hrk1-mediated signal transduction pathway in K. phaffii.

\section{Overexpression of HRK1 but not PMA1 promotes biosynthesis of 6-MSA in culture with acetate} As previously reported, a reporter compound derived from acetyl-CoA could be used for evaluation of acetylCoA production levels [42]. Acetate is directly catalyzed to acetyl-CoA in yeast; so, quantification of acetyl-CoAderived products can be used to evaluate the utilization of acetate [42]. Here, we used 6-MSA as a reporter molecule to investigate the effects of various metabolic
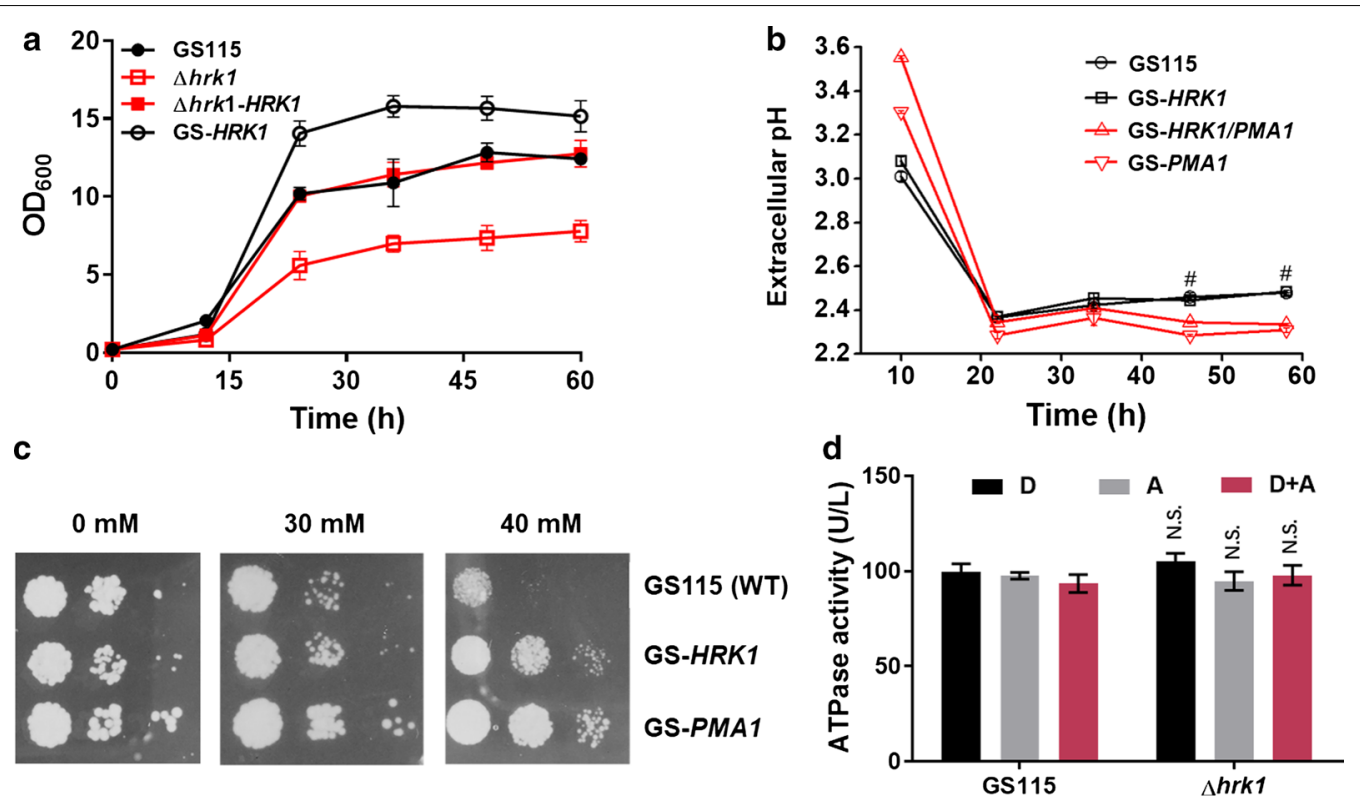

Fig. 2 Hrk1 and Pma1 functions in acetate tolerance. a Cell growth of K. phaffii wild-type GS115 (WT), $\triangle$ hrk1, $\triangle$ hrk1-HRK1 and GS-HRK1 under YND medium supplemented with $30 \mathrm{mM}$ acetate (medium pH 4.5). b The extracellular pH of GS115, GS-HRK1, GS-PMA1 and GS-HRK1/PMA1 in YND medium with initial acetate concentration of $30 \mathrm{mM}$ (medium pH 4.5). \#Significant at $P<0.05$ for GS-PMA1\&GS115 and GS-HRK1/PMA1\&GS115 at 46 and $58 \mathrm{~h}, n=6$ for each strain. c K. phaffii phenotypes of wild-type GS115 (WT), HRK1 overexpression strain (GS-HRK1) and PMA1 overexpression strain (GS-PMA1). Cells were spotted on YPD agar plates with acetate of 0,30 and $40 \mathrm{mM}$ (medium pH 4.5) at three concentrations $\left(\mathrm{OD}_{600}=0.1,0.01\right.$ and 0.001). d ATPase activity of GS1 15 and $\Delta$ hrk cultivated for $4 \mathrm{~h}$ in YND medium (pH 4.5) with different conditions. D, $1 \%(\mathrm{w} / \mathrm{v}) \mathrm{glucose}$; A, $30 \mathrm{mM}$ acetate; D+A, 1\% (w/v) glucose and $30 \mathrm{mM}$ acetate. Difference of ATPase activity between $\Delta h r k 1$ and GS1 15 was not significant (N.S.) 
engineering strategies on acetate utilization in $K$. phaffii. The 6-MSA is a simple and stable polyketide catalyzed from a fungal polyketide synthase [28]. Biosynthesis of 6-MSA uses acetyl-CoA as a starter unit and malonyl$\mathrm{CoA}$ as an extension unit, for which malonyl-CoA is synthesized from acetyl-CoA by acetyl-CoA carboxylase [28]. The 6-MSA biosynthetic pathway, consisting of the npgA gene for Aspergillus nidulans phosphopantetheinyl transferase and the at $X$ gene for Aspergillus terreus 6-methylsalicylic acid synthase, was constructed in a $K$. phaffii strain (GS-XN, abbr. XN).

Since overexpression of Hrk1 in $K$. phaffii (Fig. 1, Fig. 2) and Pma1 in K. phaffii (Fig. 2) and S. cerevisiae [43] showed positive effects on acetate tolerance, it was presumed that they might promote acetate metabolism in $K$. phaffii. Thereby, K. phaffii HRK1 and PMA1 were overexpressed in the strain XN (Additional file 1: Fig. S6). As shown in Fig. 3a, growth of strains $\mathrm{XN}, \mathrm{XN}-H R K 1$, $\mathrm{XN}-P M A 1$ and $\mathrm{XN}-H R K 1 / P M A 1$ reached stationary phase in $24 \mathrm{~h}$ without acetate. However, they could not reach a high cell density as that of the wild-type strain (Fig. 2a) because of the negative effects (antimicrobial) of 6-MSA on cells [44]. Meanwhile, they were still in exponential phase at $24 \mathrm{~h}$ in cultures with acetate. Cells in culture with $20 \mathrm{mM}$ acetate reached higher cell density as compared to that without acetate supplementation (Fig. 3a). It indicates that this low level of acetate facilitated cell growth of $K$. phaffii as an effective substrate. Differently, cell growth was not obviously improved by acetate of $30 \mathrm{mM}$ (Fig. 3a), which probably ascribes to the inhibition of cellular metabolic processes by high level of acetate [18]. Expectedly, acetate improved 6-MSA biosynthesis, and particularly, strain $\mathrm{XN}-H R K 1$ showed obvious improvement in production and productivity of 6-MSA under all acetate levels (Fig. 3b, c). The production of 6-MSA in $\mathrm{XN}-H R K 1$ reached the highest level $(133.4 \mathrm{mg} / \mathrm{L})$ on $30 \mathrm{mM}$ acetate. Also, productivity of 6-MSA in XN-HRK1 reached about $83.2 \mathrm{mg} / \mathrm{g}$ DCW on $30 \mathrm{mM}$ acetate, $55 \%$ higher than that of XN. In contrast, overexpression of $P M A 1$ had only minor effects on 6-MSA level. Additionally, co-overexpression of HRK1 and PMA1 showed positive effects on 6-MSA biosynthesis (Fig. 3b, c) and the protein expression of Hrk1 seems comparable (Additional file 1: Fig. S6). Although overexpression of HRK1 in wild-type strains promoted cell growth in medium with acetate (Fig. 2a), it did not improve cell growth in the recombinant 6-MSA-producing strain (Fig. 3a).

Generally, overexpression of PMA1 could not improve 6-MSA biosynthesis in medium with acetate in $K$. phaffii, despite that it resulted in low extracellular $\mathrm{pH}$. Overall, we inferred that Hrk1 plays an important role in acetate tolerance. Pma1, as a plasma membrane $\mathrm{H}(+)$-ATPase that is highly stable and abundant, represents $15 \%$ of all plasma membrane proteins in S. cerevisiae [42, 43]. Moreover, Pma1 plays multiple roles, such as inducing a constitutive activation of the Hog1 and Slt2 kinases of the high osmolarity glycerol (HOG) and cell wall integrity (CWI) pathways. It is also a major consumer of cellular ATP and has been estimated to consume at least $20 \%$ ATP in cells $[40,45]$. Therefore, these might affect cell metabolism, which could offset the 6-MSA production improvement attained by overexpression of HRK1.

\section{Introducing acetate transporter ScFps $1^{*}$ is unprofitable to acetate utilization and 6-MSA biosynthesis}

A possible limiting step of acetate utilization is the transport of acetate. As previously reported, several plasma membrane transporters are involved in acetate transport, including Ady2 [46], Jen1 [47], and Fps1 [17] in S. cerevisiae. Ady 2 and Jen1 are responsible for transport of a dissociated form of acetate. However, acetate is substantially undissociated at low $\mathrm{pH}$, which is exactly suitable for the growth of yeast. Fps1 is the membrane channel that facilitates passive diffusional flux of undissociated acetate into the cell in S. cerevisiae [17]. The T231A S537A double mutation of S. cerevisiae Fps1 (ScFps1") can prevent its in vivo phosphorylation and acetate continuously entering cell [17].

Blast of S. cerevisiae Fps1 (GenBank: CAA97494.1) indicates no conserved homolog in $K$. phaffii. Thus, $S$. cerevisiae Fps1 was selected as the target to promote acetate transport and, a recombinant strain (XN-ScFPS1) expressing ScFPS1" (Additional file 1: Fig. S7) was constructed and used for 6-MSA biosynthesis. Cell growth of the XN-ScFPS1* and XN strains were similar in cultures with 0,20 and $30 \mathrm{mM}$ acetate (Fig. 4a). Overexpression of ScFPS1" did not improve 6-MSA production and productivity, which were even reduced under 0 and $20 \mathrm{mM}$ acetate (Fig. 4b, c). Subcellular localization of ScFps1* and extracellular acetate concentration were further determined. Expression of a fusion protein ScFps1*-GFP indicated that ScFps1* successfully localized within the plasma membrane in $K$. phaffii (Additional file 1: Fig. S5). Nonetheless, broth residual acetate levels of wild-type GS115 and recombinant GS-ScFPS1* remained almost the same throughout the whole process in cultures with an initial acetate concentration of 20 or $30 \mathrm{mM}$ (Additional file 1: Fig. S8). Therefore, we inferred that the native acetate transport ability of $K$. phaffii was sufficient and extra expression of ScFPS1 ${ }^{*}$ did not work under these acetate levels. This phenomenon was different from that in S. cerevisiae [17]. It was reported that the maximum tolerated concentration of acetate was up to about $100 \mathrm{mM}$ in S. cerevisiae (also proved in Additional file 1: Fig. S1) $[17,19]$, much higher than the $40 \mathrm{mM}$ maximum 


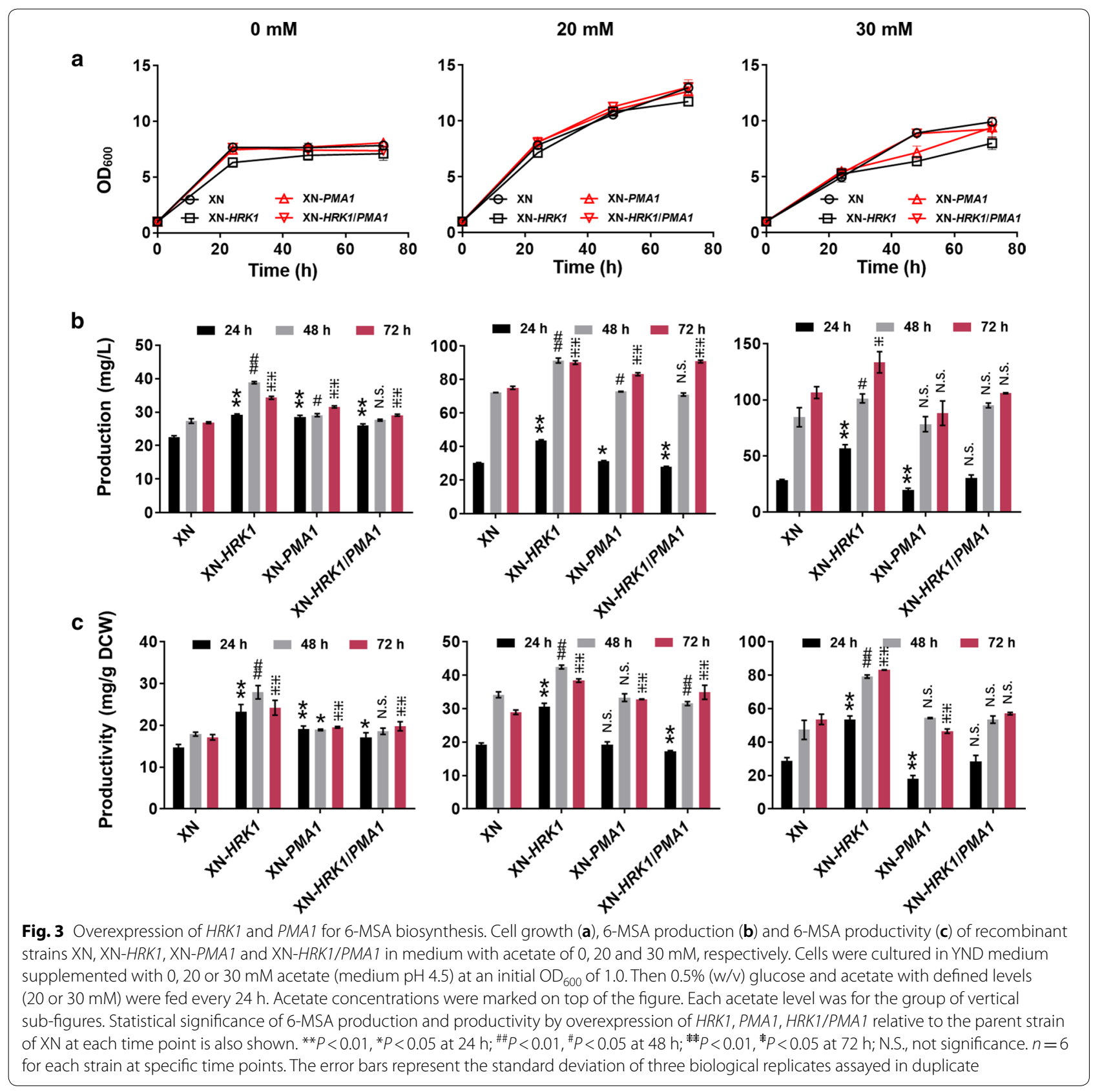

observed in K. phaffii (Additional file 1: Fig. S1). Possibly, the native high acetate transport capacity of $K$. phaffii makes it more sensitive to acetate concentrations, as compared to S. cerevisiae.

\section{Introducing yeast acetyl-CoA synthetases improves acetate utilization and 6-MSA biosynthesis}

Since the excessive accumulation of acetate intracellularly can cause damage to cells, it is necessary to engineer a fast and efficient metabolic pathway for acetate in cytosol. It has been reported that acetyl-CoA synthetase (Acs) catalyzes a limiting step due to its low activity and high energy-input requirements [14]. Substituting proline for leucine at position 641 on acetylCoA synthetase (SeAcs1) from Salmonella enterica could prevent acetylation of SeAcs1 and maintain its high catalytic activity [32]. The amino acid sequences around the acetylation site between $S$. enterica and yeast are well conserved. We then substituted proline for leucine at position 707 on ScAcs1 (GenBank: AAU09675.1) and designated it as ScAcs1". However, there is no conserved acetylation site in PpAcs1 from $K$. phaffii. Afterwards, genes encoding acetyl-CoA synthetase PpAcs1 (NCBI: XP_002491701.1) from $K$. 


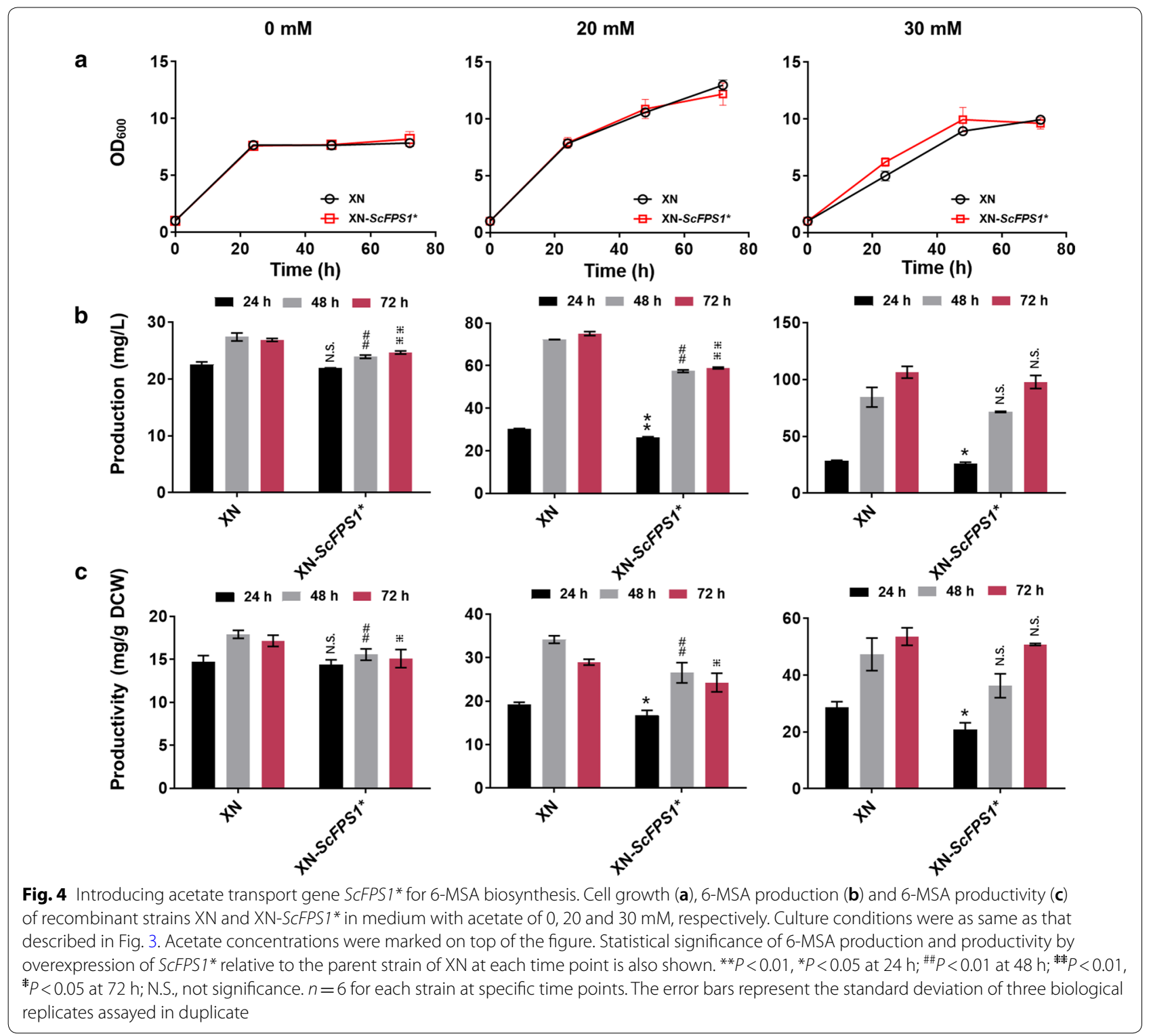

phaffii, ScAcs1" from S. cerevisiae, and acetate kinase AckA/phosphotransacetylase Pta with codon-optimized genes from E. coli (Additional file 1: Table S1), were separately overexpressed and evaluated in the strain XN (Additional file 1: Fig. S9).

Overexpression of yeast acetyl-CoA synthetase did not affect cell growth (Fig. 5a) but modulated biosynthesis of 6-MSA definitely (Fig. 5b, c). Without acetate feeding, the 6-MSA levels of XN-PpACS1, XN-ScACS1" and $\mathrm{XN}-\mathrm{Pta} / A c k A$ were almost the same as that of $\mathrm{XN}$. However, with $20 \mathrm{mM}$ acetate feeding, biosynthesis of 6-MSA from XN-PpACS1 and XN-ScACS1" was significantly improved. The 6-MSA productivity of XN-PpACS1 and XN-ScACS1" achieved about 63.5 and $63.7 \mathrm{mg} / \mathrm{g}$ cell at $48 \mathrm{~h}$, respectively, 1.20 and 1.21 times higher than in $\mathrm{XN}$. Nonetheless, overexpression of PpACS1 or ScACS1 $1^{*}$ did not improve 6-MSA biosynthesis on $30 \mathrm{mM}$ acetate. Besides, overexpression of ptalackA more or less impaired cell growth and biosynthesis of 6-MSA in XN-ptalackA also reduced as compared to that in $\mathrm{XN}$ under all conditions. As is reported, the acetate kinase/phosphotransacetylase (Ack/Pta) route is reversible. It assimilates acetate in relatively high concentration, as both enzymes possess high $K_{m}$ values for their substrates in E. coli [11]. Thus, acetyl-CoA accumulation might be weakened due to the reversible conversion of acetate into acetylCoA, which will further affect cell growth and 6-MSA biosynthesis. 
$\mathbf{0} \mathbf{~ m M}$

a

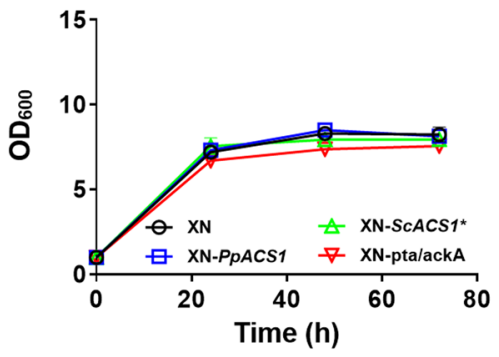

b

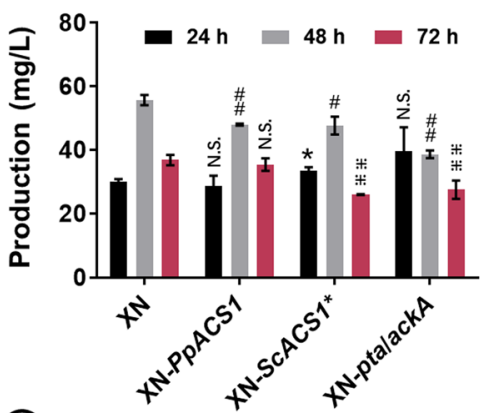

C

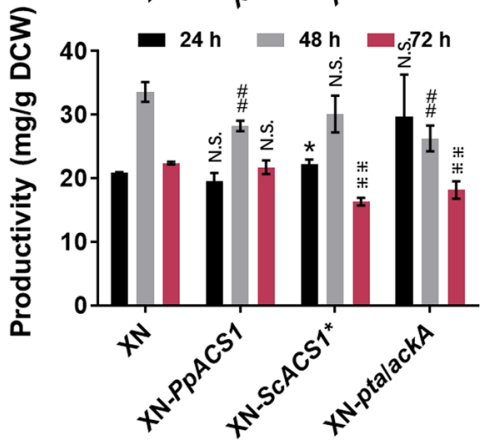

$20 \mathrm{mM}$
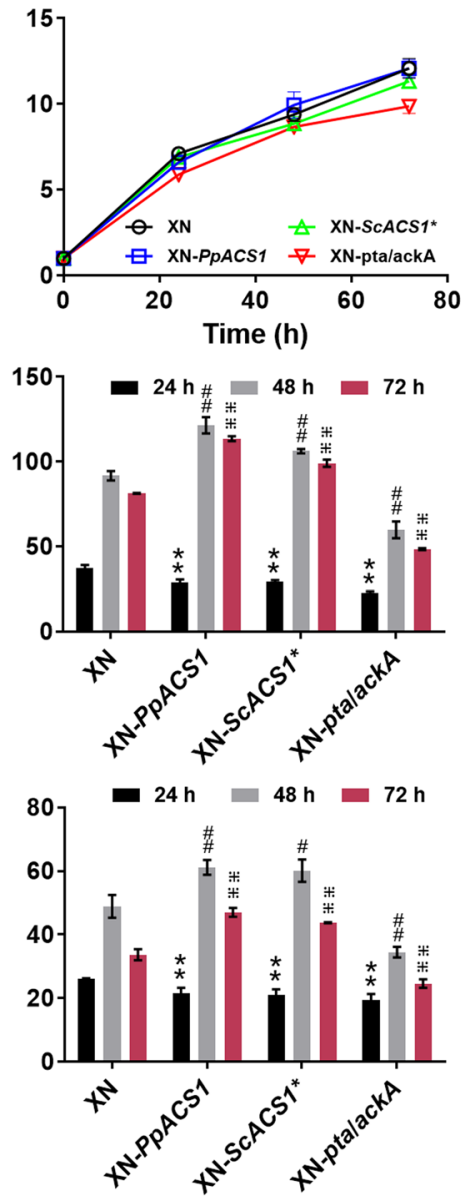

$30 \mathrm{mM}$
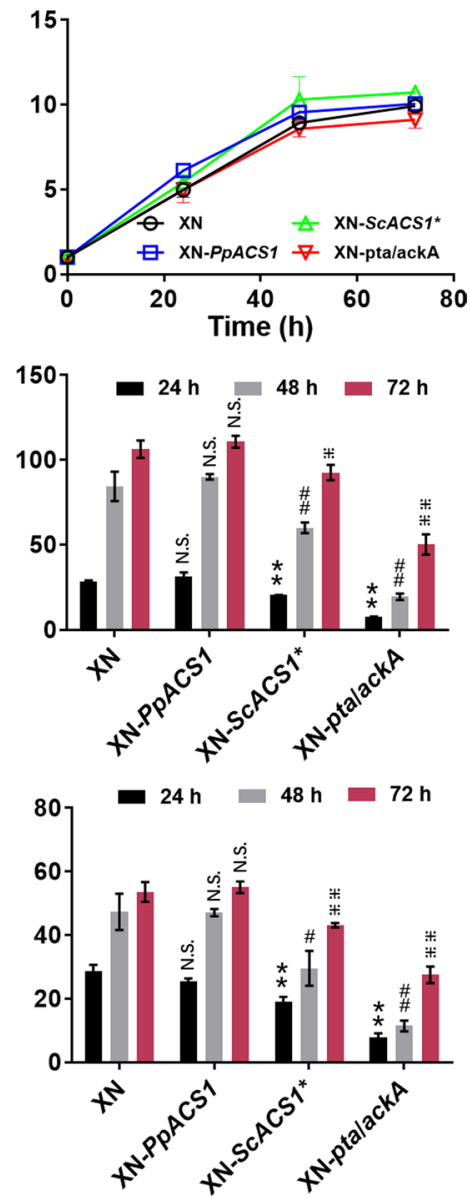

Fig. 5 Overexpression of yeast acetyl-CoA synthetase and E. coli acetate kinase/phosphotransacetylase gene for 6-MSA biosynthesis. Cell growth (a), 6-MSA production (b) and 6-MSA productivity (c) of recombinant strains XN, XN-PpACS1, XN-SCACS1* and XN-pta/ackA in medium with acetate of 0,20 and $30 \mathrm{mM}$, respectively. Culture conditions were as same as that described in Fig. 3. Acetate concentrations were marked on top of the figure. Acetate concentrations were marked the same as those in Fig. 3. Statistical significance of 6-MSA production and productivity by overexpression of $P$ PACS1, SCACS1 ${ }^{*}$ and pta/ackA relative to the parent strain of $X N$ at each time point is also shown. ${ }^{*} P<0.01,{ }^{*} P<0.05$ at 24 h; ${ }^{\#} P<0.01,{ }^{\#} P<0.05$ at $48 \mathrm{~h}$; ${ }^{* * *} P<0.01,{ }^{*} P<0.05$ at $72 \mathrm{~h}$; N.S., not significance. $n=6$ for each strain at specific time points. The error bars represent the standard deviation of three biological replicates assayed in duplicate. PpAcs1, acetyl-CoA synthetase from K. phaffii. ScAcs 1*, acetyl-CoA synthetase from S. cerevisiae. AckA, E. coli acetate kinase. Pta, E. coli phosphotransacetylase

\section{Co-overexpression of HRK1 and SCACS1 ${ }^{*}$ gives synergy effect}

Overexpression of Hrk1, PpAcs1 or ScAcs1" separately has improved utilization of acetate and biosynthesis of its derived polyketide, 6-MSA. Therefore, co-overexpression of HRK1/PpACS1 or HRK1/ScACS1" (Additional file 1: Fig. S10) was tested to investigate the possible cooperativity of both enzymes in acetate utilization.

As shown in Fig. 6a, co-overexpression of $H R K 1 / P p A C S 1$ affected cell growth in medium with acetate, as compared to HRK1/ScACS1" co-overexpressing strain and the wild type. With $20 \mathrm{mM}$ acetate feeding, biosynthesis of 6-MSA from XN-HRK1-ScACS1" highly increased and the production and productivity of 6-MSA reached $113.6 \mathrm{mg} / \mathrm{L}$ and $44.6 \mathrm{mg} / \mathrm{g} \mathrm{DCW}$ (Fig. 6b, c), $45 \%$ and $51 \%$ higher than the control $(\mathrm{XN})$, respectively. Analyzing the 6-MSA production and productivity ratio of the overexpression strain to its control $\mathrm{XN}$ strain in each batch, we may find that co-overexpression of HRK1/ScACS1" enhanced 6-MSA biosynthesis, compared with single gene expressing strains of XN-HRK1 (Fig. 3) and XN-ScACS1 ${ }^{*}$ (Fig. 5) under the same acetate feeding concentration of $20 \mathrm{mM}$. Although individual expression of PpACS1 and ScACS1" showed similar effects on cell growth and 6-MSA production in medium with acetate, they differed greatly when co-expressed with HRK1. An investigation is underway to reveal the background of this phenomenon. Moreover, although 
$0 \mathrm{mM}$

a

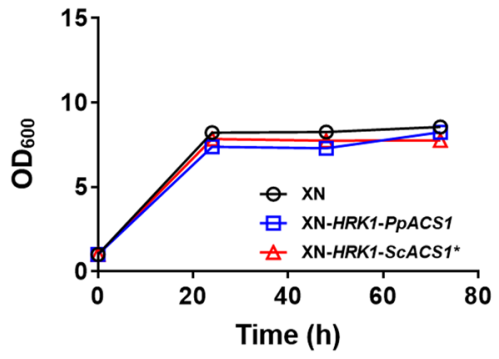

b

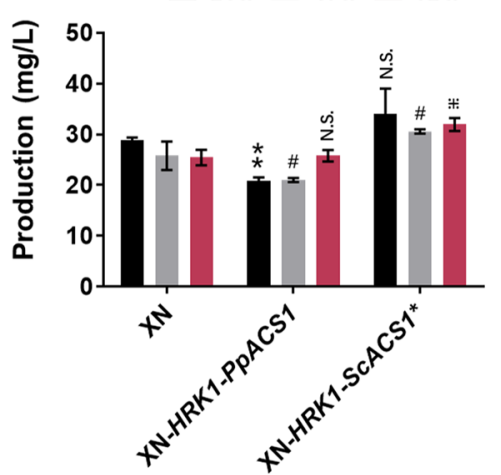

C

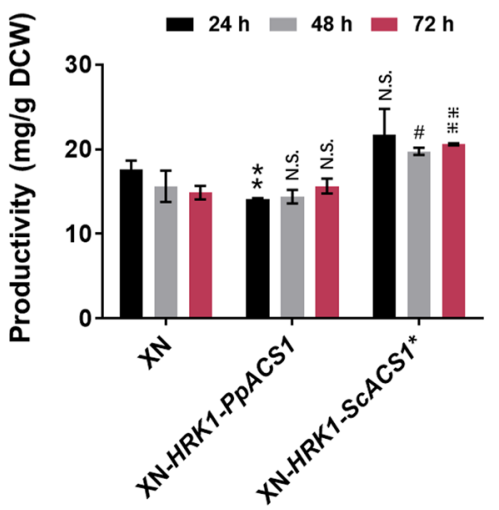

$20 \mathrm{mM}$

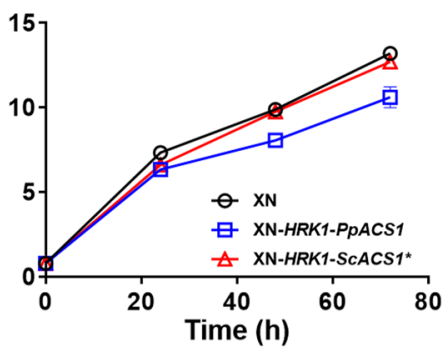

- $24 \mathrm{~h}-48 \mathrm{~h}=72 \mathrm{~h}$

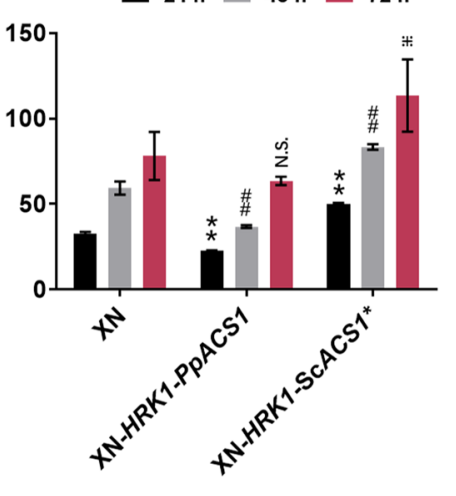

- $24 \mathrm{~h} \square 48 \mathrm{~h} \square 72 \mathrm{~h}$

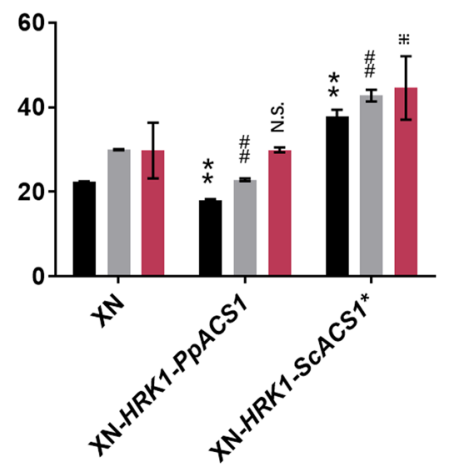

$30 \mathrm{mM}$

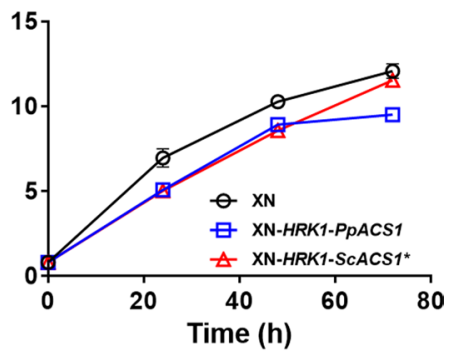

- $24 \mathrm{~h}=48 \mathrm{~h}=72 \mathrm{~h}$

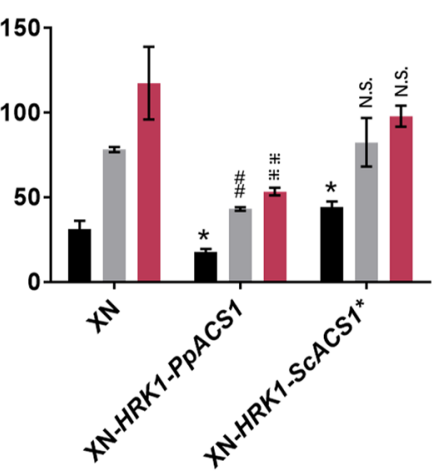

- $24 \mathrm{~h}-48 \mathrm{~h} \square 72 \mathrm{~h}$

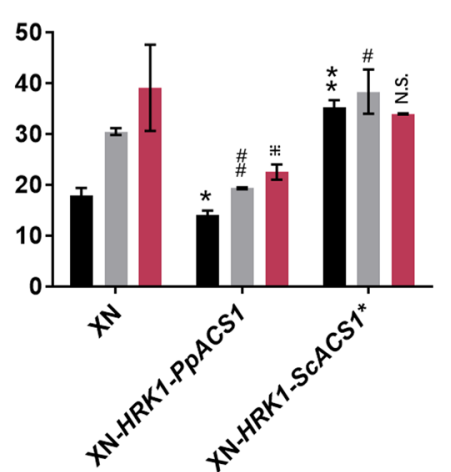

Fig. 6 Co-overexpression of HRK1/SCACS1*, HRK1/PPACS1 for 6-MSA biosynthesis. Cell growth (a), 6-MSA production (b) and 6-MSA productivity (c) of recombinant strains XN, XN-HRK1-PpACS1 and XN-HRK1-SCACS1* in medium with acetate of 0,20 and $30 \mathrm{mM}$, respectively. Culture conditions were as same as that described in Fig. 3. Acetate concentrations were marked on top of the figure. Acetate concentrations were marked the same as those in Fig. 3. Statistical significance of 6-MSA production and productivity by overexpression of PpACS1, SCACS1* and pta/ackA relative to the parent strain of $X N$ at each time point is also shown. ${ }^{*} P<0.01,{ }^{*} P<0.05$ at $24 \mathrm{~h}$; ${ }^{\# \#} P<0.01,{ }^{\#} P<0.05$ at $48 \mathrm{~h}$; ${ }^{*}: \|^{*} P<0.01$, ${ }^{*} P<0.05$ at $72 \mathrm{~h}$; N.S., not significance. $n=6$ or 9 for each strain at specific time points. The error bars represent the standard deviation of three biological replicates assayed in duplicate or triplicate

co-overexpression of $H R K 1 / S c A C S 1^{*}$ greatly improved production and productivity of 6-MSA in $K$. phaffii under acetate feeding of $20 \mathrm{mM}$, the degree of promotion was still lower than that observed with HRK1 single gene expression strain with 6-MSA production of $133.4 \mathrm{mg} / \mathrm{L}$ and productivity of $83.2 \mathrm{mg} / \mathrm{g}$ DCW under acetate feeding of $30 \mathrm{mM}$ (Fig. 3b, c). Then, the transcriptional level of HRK1 in HRK1/PpACS1 or HRK1/ScACS1" co-overexpressing strain was analyzed and they both declined compared with the HRK1 single gene expression strain
(Fig. S11). Also, the protein expression of Hrk1 highly decreased in cells of XN-HRK1-PpACS1 and XN-HRK1ScACS1" (Additional file 1: Fig. S10).

As genes expression was driven by GAP promoter, increase of heterologous genes controlled by this same promoter will have a 'titration' effect on transcription factors, and thus reduce gene expression strength [48, 49]. Thus, the transcription 'titration' effect also happened here, which more or less offset the expected synergy improvement effects on 6-MSA biosynthesis. Moreover, 
as $K$. phaffii cells are sensitive to high acetate concentration, involvement of more heterologous genes and enzymes under this condition will aggravate physiological and metabolic stress, which may further affect 6-MSA biosynthesis. Although Hrk1 plays an important role in acetate tolerance, its function is not implicated in the activation of the plasma membrane $\mathrm{H}(+)$-ATPase Pmal as its gene annotation describes. Therefore, it is important to search for the possible targets of Hrk1. Clarifying the targets and regulation modes of Hrk1 may provide more ideas for improvement of acetate tolerance in $K$. phaffii. Besides, improvement of acetate metabolism is also crucial to acetate utilization. It not only promotes the metabolism of acetate, but also relieves the adverse effect of acetate to cells to some extent. Our results proved that co-expression of HRK1 and ScACS1" under the promoter of $\mathrm{P}_{G A P}$ remarkably improves the acetate utilization. Nonetheless, metabolism of acetate could be further advanced. Use of different promoters to express $H R K 1$ and $S c A C S 1^{*}$ and balance their expression to adapt to cells is also necessary to further facilitate acetate utilization in $K$. phaffii.

\section{Conclusions}

Komagataella phaffii has shown good potential for use in biomanufacturing, but its high sensitivity to acetate presents problems for the use of acetate as a substrate for acetyl-CoA-derived chemicals. This study finds a native kinase of Hrk1 that plays an important role in acetate tolerance from a kinase-deficient library in $K$. phaffii. It provides a potential target for metabolic engineering of acetate tolerance in eukaryotic expression hosts. Also, improved acetate metabolism can be achieved by overexpression of yeast acetyl-CoA synthetases. Co-overexpression of Hrk1 and acetyl-CoA synthetase ScAcs1" successfully improved production of acetyl-CoA-derived heterologous compound in $K$. phaffii. This work provides reference to the production of pharmaceuticals and chemicals with acetate as carbon source or precursor in K. phaffii.

\section{Methods}

\section{Strains, media and growth conditions}

Escherichia coli Top10, K. phaffii GS115 and expression vectors of pPIC3.5 K and pGAPZ $\alpha \mathrm{A}$ were purchased from Invitrogen. The pAG32 vector $\left(\mathrm{Hyg}^{R}\right)$ was kindly provided by Prof. Saurabh Joshi (University of California, San Diego). S. cerevisiae S288c was kindly provided by Prof. Qiang Hua (East China University of Science and Technology).

The E. coli strains were grown in light Luria-Bertani $(1 \%[\mathrm{w} / \mathrm{v}]$ Bacto peptone, $0.5 \%[\mathrm{w} / \mathrm{v}]$ yeast extract and $1 \%[\mathrm{w} / \mathrm{v}]$ sodium chloride) medium at $37{ }^{\circ} \mathrm{C}$, and $100 \mu \mathrm{g} /$
$\mathrm{mL}$ of ampicillin or $50 \mu \mathrm{g} / \mathrm{mL}$ of Zeocin was added to the medium when required. Yeast for seed preparation was incubated at $30{ }^{\circ} \mathrm{C}$ in YPD $(2 \%[\mathrm{w} / \mathrm{v}]$ Bacto peptone, $1 \%$ $[\mathrm{w} / \mathrm{v}]$ yeast extract and $2 \%[\mathrm{w} / \mathrm{v}]$ glucose) medium. And $100 \mu \mathrm{g} / \mathrm{mL}$ of Zeocin or $0.75 \mathrm{mg} / \mathrm{mL}$ of Hygromycin B was added to the YPD medium when required. 6-Methylsalicylic acid (6-MSA)-producing strains were cultured in synthetic YND medium containing 1.34\% (w/v) YNB (yeast nitrogen base without amino acids), 1\% (w/v) glucose and acetate with defined levels, and the medium $\mathrm{pH}$ was adjusted to 4.5 before sterilization.

\section{Construction of plasmids and strains}

The gene HRK1 (NCBI: XM_002493292.1), PMA1 (NCBI: XM_002489588.1) and PpACS1 (NCBI: XM_002491656.1) were amplified from the genomic DNA of $K$. phaffii GS115. The gene ScFPS1" (NCBI: NC_001144.5) was cloned by three fragments with various primers (GAPZa-Scfps1-F/Scfps1-1(S-A)-R, Scfps1-1(S-A)-F/Scfps1-2(T-A)-R, Scfps1-2(T-A)-F/ Scfps1-pGAPZ-R) from S. cerevisiae S288c to introduce the mutation of S231A and T537A. The gene ScACS1" (GenBank: AY723758.1) was amplified from S. cerevisiae S288c by primers of ScAcs1"-pGAP-F/ScAcs1"L-P-pGAPZ-R which contain the mutation of L707P. The gene ackA (NCBI: NP_311207.1) and pta (NCBI: NP_416800.1) from E. coli were codon-optimized and synthesized by Suzhou Genewiz Biotech Co., Ltd., China. The mutant genes of ScFPS1 and ScACS1 were denoted as SCFPS1" and SCACS1".

The gene npgA (GenBank: AAF12814.1) from Aspergillus nidulans and gene atX (GenBank: D85860.2) from Aspergillus terrus were amplified and cloned into pGAPZ $\alpha$ A linearized with KpnI/BspT104I to construct pGAPZ- $n p g A$ and pGAPZ-atX. The plasmid pPICZB$n p g A$ was generated by inserting $n p g A$ expression cassette into pPICZ B linearized with BglII/EcoRI. The plasmid pPICZB-npgA/at $X$ was generated by inserting at $X$ expression cassette into pPICZB-npgA linearized with SpeI. The plasmid pPIC-apgA/atX-AOX was generated by inserting $5 A O X 1$ into pPICZB-npgA/atX linearized with SpeI. The strain GS-XN (abbr. XN) was constructed by transforming linearized plasmid pPIC-npgA/atX-AOX by pmeI into K. phaffii GS115 by electroporation.

The plasmids pGAPZ-HRK1, pGAPZ-PMA1, pGAPZ$P p A C S 1$ and pGAPZ-SCACS1" were generated by inserting HRK1, PMA1, PpACS1 and ScACS1 ${ }^{*}$ genes into the vector pGAPZ $\alpha A$ linearized with $K p n \mathrm{I} / B s p T 104 \mathrm{I}$ by a ClonExpress II one step cloning kit (catalog no. C112, Vazyme), respectively. The plasmid pGAPZ-ScFPS1" was generated by assembling three fragments of $S c F P S 1$ genes with vector pGAPZ $\alpha$ A linearized with $K p n \mathrm{I} / B s p T 104 \mathrm{I}$ by a ClonExpress MultiS one-step cloning kit (catalog 
no. C113, Vazyme). All these genes assembled with pGAPZ $\alpha$ A were under the control of the GAP promoter $\left(\mathrm{P}_{G A P}\right)$, and the expression cassette of these genes including $\mathrm{P}_{G A P}$ was amplified by PCR.

The plasmid pAG32-PMA1 was generated by inserting PMA1 expression cassette amplified by primers of pAG32DHind3-GAP-F/pAG32BamH1-TT-R into pAG32 linearized with HindIII/BamHI. The plasmid pAG32-HRK1/PMA1 was generated by assembling linearized pAG32-PMA1 with SpeI and HRK1 expression cassette amplified by primers of pAG32-pGAP-F/ pAG32-spe1-TT-R. The plasmid pAG32-5AOX was generated by inserting $5^{\prime}$ fragment of $A O X 1$ amplified by primers of pAOX-pAG32Spe1-F/pAOX-pAG32-R with pAG32 linearized with SpeI to get the integration site for $K$. phaffii genome. The plasmids pAG32-5AOXHRK1 and pAG32-5AOX-ScFPS1* were generated by inserting HRK1 and ScFPS1" expression cassette amplified by primers of pAG32-pGAP-F/AOXTT-Spe1pAOX-R with pAG32-5AOX linearized with SpeI. The plasmids pPIC3.5 K-PpACS1, pPIC3.5 K-ScACS1" and pPIC3.5 K-ackA were generated by inserting PpACS1, $S c A C S 1^{*}$ and ackA expression cassettes amplified by primers of GAP-3.5KSpe1-F/His6-3.5 k-R into pPIC3.5 K linearized with $\mathrm{SacI} / \mathrm{Not} \mathrm{I}$, respectively. The plasmid pPIC3.5 K-pta/ackA was generated by inserting pta expression cassettes amplified by primers of GAP3.5 KSpe1-F/GAP-3AOX-R into pPIC3.5 K-ackA linearized with SpeI. The plasmids pAG32-PMA1-gfp and pAG32-5AOX-SCFPS1 ${ }^{*}$-gfp were generated by inserting $g f p$ fragment amplified by primers of pma1-GFP-F/ GFP-xhomyc-R and Scfps"-GFP-F/GFP-xhomyc-R into pAG32-PMA1 and pAG32-5AOX-ScFPS1* linearized with XhoI.

The plasmids pAG32-PMA1 and pAG32-HRK1/PMA1 were linearized by $S t u \mathrm{I}$, the plasmids pAG32-5AOXHRK1 and pAG32-5AOX-ScFPS1" were linearized by pmeI, the plasmids pPIC3.5K-PpACS1, pPIC3.5K$S c A C S 1^{*}$ and pPIC3.5K-pta/ackA were linearized by $B s p E I$. All these linearized plasmids were transformed into a 6-MSA producing strain GS-XN by electroporation. Meanwhile, linearized pAG32-HRK1, pAG32PMA1, pAG32-HRK1/PMA1 and pAG32-SCFPS1" were transformed into $K$. phaffii GS115. Linearized pAG32-HRK1 was transformed into $\Delta h r k 1$. The plasmids pAG32-PMA1-gfp linearized with $S t u \mathrm{I}$ and pAG32-5AOX-ScFPS1 $1^{*}-g f p$ linearized with pmeI were transformed into $K$. phaffii GS115. All of the plasmids and strains used in this study were summarized in Additional file 1: Tables S2, S3. All of the primers used in this work are summarized in Additional file 1: Table S4.

\section{Acetate tolerance assay}

Strains from the $K$. phaffii kinase deletion library [31] were pre-grown in YPD medium to $\mathrm{OD}_{600}$ of 2.0-8.0. Then the cells were harvested by centrifugation at $5000 \mathrm{~g}$ for $3 \mathrm{~min}$ and washed three times with sterile water. Acetate solution of $2 \mathrm{M}$ was prepared and $\mathrm{pH}$ was adjusted to 4.5 with $\mathrm{NaOH}$. Cell suspensions were spotted $5 \mu \mathrm{L}$ in three dilutions $\left(\mathrm{OD}_{600}\right.$ of $0.1,0.01$ and 0.001$)$ on YPD agar plates, supplemented with acetate to the final concentration of 0,30 and $40 \mathrm{mM}$ (medium $\mathrm{pH} 4.5$ ), respectively. Cell growth was monitored over 2 days at $30^{\circ} \mathrm{C}$.

\section{ATPase activity assay}

Strains of $K$. phaffii GS115 and $\Delta h r k 1$ were pre-grown in YPD medium to $\mathrm{OD}_{600}$ of 2.0-8.0; then, the cells were harvested by centrifugation and washed three times with sterile water. Then, cell suspensions were inoculated into YND medium $(\mathrm{pH}=4.5)$ at an initial $\mathrm{OD}_{600}$ of 1.0, supplemented with $1 \%(\mathrm{w} / \mathrm{v})$ glucose, $30 \mathrm{mM}$ acetate or $1 \%$ glucose $(\mathrm{w} / \mathrm{v})+30 \mathrm{mM}$ acetate, respectively. Cells were harvested after 4-h culture shaking at $200 \mathrm{rpm}$ and $30^{\circ} \mathrm{C}$.

Total protein extracts were purified as described previously [41]. The yeast cells were vortexed with zirconium beads in $25 \mathrm{mM}$ Tris- $\mathrm{HCl}$ (pH 8.0), $5 \mathrm{mM}$ EDTA. A protease inhibitor cocktail and a phosphatase inhibitor cocktail (catalog no. P1060, Beyotime) were added prior to cell breakage. The homogenate was cleared from intact cells by centrifugation at $300 \mathrm{~g}$ for $5 \mathrm{~min}$. The supernatant was then centrifuged at $12,000 \mathrm{~g}$ for $30 \mathrm{~min}$. The resulting pellet was suspended in buffer containing $20 \%(\mathrm{w} / \mathrm{v})$ glycerol, $50 \mathrm{mM}$ Tris- $\mathrm{HCl}$ (pH 8), $5 \mathrm{mM}$ EDTA, $2 \mathrm{mM}$ 1, 4-dithioerythritol (DTT) and phosphatase inhibitor cocktail. In those samples used to measure ATPase activity, the phosphatase inhibitor cocktail was omitted in all steps. ATPase activity was measured by ATPase/GTPase activity assay kit (catalog no. MAK113, Sigma-Aldrich) with 2 mM ATP (catalog no. A600020, Sangon).

\section{Western blot analysis}

For each strain, yeast cells (equivalent to cells from $30 \mathrm{~mL}$ broth of $\mathrm{OD}_{600}=1$ ) were harvested after 32 -h culture by centrifugation at $3000 \mathrm{~g}, 4{ }^{\circ} \mathrm{C}$ for $5 \mathrm{~min}$. The precipitate was washed twice with ice-cold $50 \mathrm{mM}$ binding buffer $\left(10 \mathrm{mmol} / \mathrm{L} \mathrm{NaH}_{2} \mathrm{PO}_{4}, 10 \mathrm{mmol} / \mathrm{L} \mathrm{Na}_{2} \mathrm{HPO}_{4}, 0.5 \mathrm{~mol} / \mathrm{L}\right.$ $\mathrm{NaCl}, 20 \mathrm{mmol} / \mathrm{L}$ imidazole, $\mathrm{pH} 7.4$ ), and then resuspended in $1 \mathrm{~mL}$ binding buffer. Afterwards, cells were mechanically disrupted by a high-pressure homogenizer for protein analysis. Protein bands were separated by $12 \%$ SDS-PAGE and transferred to nitrocellulose membranes. The membranes were incubated with $10 \%$ non-fat powdered milk in phosphate-buffered saline containing $0.1 \%$ Tween 20 (PBST) for blocking, and then reacted with $6 \times$ His-tag antibody (1:2000 dilution, Beyotime). 
Secondary antibodies (1:1000 dilution, Beyotime) conjugated with horseradish peroxidase were used and immunoreactive proteins were detected with BeyoECL Plus (Beyotime).

\section{6-Methylsalicylic acid analysis}

6-Methylsalicylic acid (6-MSA)-producing strains were pre-grown in $50 \mathrm{~mL}$ YPD medium to $\mathrm{OD}_{600}$ of 2.0-8.0; then the cells were harvested by centrifugation at $3000 \mathrm{~g}$ for $5 \mathrm{~min}$ and washed three times with sterile water. The obtained cells were inoculated into YND medium, supplemented with 0,20 or $30 \mathrm{mM}$ acetate, at an initial $\mathrm{OD}_{600}$ of 1.0, and cultured for $72 \mathrm{~h}$. During culture phase, $5 \mathrm{~mL}$ broth sample was taken out for analysis every $24 \mathrm{~h}$. Meanwhile, $0.5 \%(\mathrm{w} / \mathrm{v})$ glucose and acetate with defined levels $(20$ or $30 \mathrm{mM}$ ) were fed into culture broth every $24 \mathrm{~h}$.

After culture for $72 \mathrm{~h}, 5 \mathrm{ml}$ culture broth was mixed with $10 \mathrm{ml}$ ethyl acetate and vortex oscillated for $2 \mathrm{~min}$. The organic phase was evaporated under reduced pressure and dissolved in methanol. The 6-MSA in extracts was quantified by a high-performance liquid chromatograph (Agilent Technologies 1260 series) equipped with a $\mathrm{C}_{18}$ reverse column (Kromasil ${ }^{\mathrm{TM}}$, Sweden, $250 \mathrm{~mm} \times 4.6 \mathrm{~mm} \times 5 \mu \mathrm{m}, 100 \AA$-spherical silica) with a gradient elution strategy at $1 \mathrm{ml} / \mathrm{min}$ and detection by $\mathrm{UV}$ at $308 \mathrm{~nm}$. Acetate solution ( $0.1 \%$, phase A) and acetonitrile $(100 \%$, phase B) were used as the mobile phase. The sample was subjected to an elution gradient with a mobile phase comprising $25-65 \%$ phase A for $20 \mathrm{~min}$ followed by $65-100 \%$ phase B for $5 \mathrm{~min}$.

\section{Transcriptional level assays}

Strains were pre-cultured in YPD medium, and inoculated into YND medium supplemented with $30 \mathrm{mM}$ acetate, at an initial $\mathrm{OD}_{600}$ of 1.0. After culturing for $24 \mathrm{~h}$, yeast cells equivalent to those in $1 \mathrm{~mL}$ broth of $\mathrm{OD}_{600}$ of 20.0 were harvested by centrifugation. Total RNA of these cells was extracted using yeast total RNA isolation kit (catalog no. B518657, Sangon). Reverse transcription of $1 \mu \mathrm{g}$ mRNA was performed following FastKing RT Kit (catalog no. KR116, TIANGEN). Real-Time PCR was used to analyze transcriptional level under SuperReal PreMix Plus (SYBR Green) (catalog no. FP205, TIANGEN). The transcriptional level of HRK1 gene in strain $\mathrm{XN}-H R K 1$ was used as the control.

\section{Other analytical methods}

Cell growth was monitored by measuring $\mathrm{OD}_{600}$ using a UV-vis spectrophotometer. Dry cell weight was used for biomass calculation. Cells were centrifugated at $12,000 \mathrm{~g}$ and washed by deionized water for three times.
The obtained cells were dried at $70{ }^{\circ} \mathrm{C}$ to constant cell weight (dry cell weight). It was measured that $\mathrm{OD}_{600}$ of 1.0 makes the equivalent of dry cell weight of $0.2 \mathrm{~g} / \mathrm{L}$. Extracellular $\mathrm{pH}$ was measured manually by $\mathrm{pH}$ meter (catalog no. B-712, Horiba). Acetate level in extracellular supernatant was directly analyzed by enzymatic assays (catalog no. K-ACETRM, Megazyme). Fluorescence of the constructed strains (GS-gfp, GS-PMA1-gfp and GS-ScFPS1*-gfp) was observed by inverted microscope DMI3000B (Leica) using a $100 \times$ oil immersion objective. Images were processed using Leica application suite (version 2.8.1).

\section{Statistical analysis}

The data were obtained from three biological replicates assayed in duplicate or triplicate, and presented as mean \pm S.D. The independent samples student's $t$ test was performed to determine the differences among grouped data. Statistical significance was assessed at $P<0.05$ and $P<0.01$.

\section{Additional file}

Additional file 1. Additional figures and tables.

\section{Authors' contributions}

$\mathrm{MC}$ conceived the project. QX performed most of the experiments. CB completed the western blotting experiments. LS, LT, YY, JZ participated in part of the HRK1 expression and evaluation experiments. QX and MC analyzed the results and prepared the manuscript. $Y L, X Z, Y Z$ participated in discussion of results. $Y Z$ reviewed the manuscript. All authors have read and approved the final manuscript.

\section{Author details \\ ${ }^{1}$ State Key Laboratory of Bioreactor Engineering, East China University of Sci- ence and Technology, Shanghai 200237, China. ${ }^{2}$ Shanghai Collaborative Innovation Center for Biomanufacturing, Shanghai 200237, China.}

\section{Acknowledgements}

Not applicable.

Competing interests

The authors declare that they have no competing interests.

\section{Availability of data and materials}

The materials and datasets for the current study are available from the corresponding author on reasonable request.

\section{Consent for publication}

Not applicable.

Ethics approval and consent to participate

Not applicable.

\section{Funding}

This work was supported by the National Key R\&D Program of China (2018YFC1706200), National Natural Science Foundation of China (31870073), Fundamental Research Funds for the Shanghai Science and Technology 
Innovation Action Plan (17JC1402400), Shanghai Rising-Star Program (19QA1402700), the 111 Project (B18022), Fundamental Research Funds for the Central Universities (22221818014), Research Program of State Key Laboratory of Bioreactor Engineering and Talent Program of School of Biotechnology in East China University of Science and Technology.

\section{Publisher's Note}

Springer Nature remains neutral with regard to jurisdictional claims in published maps and institutional affiliations.

Received: 31 December 2018 Accepted: 11 March 2019

Published online: 21 March 2019

\section{References}

1. Xu BQ, Sun K, Zhu Q, Sachtler WMH. Unusual selectivity of oxygenate synthesis - formation of acetic acid from syngas over unpromoted Rh in NaY zeolite. Catal Today. 2000;63:453-60.

2. Munasinghe PC, Khanal SK, Pandey A. Biomass-derived syngas fermentation into biofuels: opportunities and challenges. Bioresour Technol. 2010;101:5013-22.

3. Zhu Z, Sathitsuksanoh N, Vinzant T, Schell DJ, Mcmillan JD, Zhang YHP. Comparative study of corn stover pretreated by dilute acid and cellulose solvent-based lignocellulose fractionation: enzymatic hydrolysis, supramolecular structure, and substrate accessibility. Biotechnol Bioeng 2009;103:715-24.

4. Ni C, Wu X, Jin D, Du D, Ni C, Wu X, et al. Facile recovery of acetic acid from waste acids of electronic industry via a partial neutralization pretreatment (PNP)_Distillation strategy. Sep Purif Technol. 2014;132:23-6.

5. Gong Z, Shen H, Zhou W, Wang Y, Yang X, Zhao ZK. Efficient conversion of acetate into lipids by the oleaginous yeast Cryptococcus curvatus. Biotechnol Biofuels. 2015;8:189.

6. Christophe G, Deo JL, Kumar V, Nouaille R, Fontanille P, Larroche C. Production of oils from acetic acid by the oleaginous yeast Cryptococcus curvatus. Appl Biochem Biotechnol. 2012;167:1270-9.

7. Li Y, Huang B, Wu H, Li Z, Ye Q, Zhang YP. Production of succinate from acetate by metabolically engineered Escherichia coli. ACS Syn Biol. 2016;5:1299-307.

8. Xiao Y, Ruan Z, Liu Z, Wu SG, Varman AM, Liu Y, et al. Engineering Escherichia coli to convert acetic acid to free fatty acids. Biochem Eng J. 2013;2013(76):60-9.

9. Gerstmeir R, Wendisch VF, Schnicke S, Ruan H, Farwick M, Reinscheid D, et al. Acetate metabolism and its regulation in Corynebacterium glutamicum. J Biotechnol. 2003;104:99-122.

10. Chen Y, Siewers V, Nielsen J. Profiling of cytosolic and peroxisomal acetylCoA metabolism in Saccharomyces cerevisiae. PLoS ONE. 2012;7:e42475.

11. Brown TD, Jones-Mortimer MC, Kornberg HL. The enzymic interconversion of acetate and acetyl-coenzyme A in Escherichia coli. J Gen Microbiol. 1977; 102:327-36.

12. Xue Y, Kong C, Shen W, Bai C, Ren Y, Zhou X, et al. Methylotrophic yeast Pichia pastoris as a chassis organism for polyketide synthesis via the full citrinin biosynthetic pathway. J Biotechnol. 2017;242:64-72.

13. Shiba Y, Paradise EM, Kirby J, Ro DK, Keasling JD. Engineering of the pyruvate dehydrogenase bypass in Saccharomyces cerevisiae for high-level production of isoprenoids. Metab Eng. 2007;9:160-8.

14. Krivoruchko A, Zhang Y, Siewers V, Chen Y, Nielsen J. Microbial acetyl-CoA metabolism and metabolic engineering. Metab Eng. 2015;28:28-42.

15. Lambert RJ, Stratford M. Weak-acid preservatives: modelling microbial inhibition and response. J Appl Microbiol. 1999;86:157-64.

16. Wei N, Quarterman J, Kim SR, Cate JHD, Jin YS. Enhanced biofuel production through coupled acetic acid and xylose consumption by engineered yeast. Nat Commun. 2013;4:2580.

17. Mollapour M, Piper PW. Hog1 mitogen-activated protein kinase phosphorylation targets the yeast Fps1 aquaglyceroporin for endocytosis, thereby rendering cells resistant to acetic acid. Mol Cell Biol. 2007;27:6446-56.

18. Arneborg N, Jakobsen M, Jespersen L. Individual cells of Saccharomyces cerevisiae and Zygosaccharomyces bailii exhibit different short-term intracellular pH responses to acetic acid. Arch Microbiol. 2000;174:125-8.
19. Ludovico P, Sousa MJ, Silva MT, Leão C, Côrte-Real M. Saccharomyces cerevisiae commits to a programmed cell death process in response to acetic acid. Microbiology. 2001;147:2409-15.

20. Carmelo V, Santos H, Sá-Correia I. Effect of extracellular acidification on the activity of plasma membrane ATPase and on cytosolic and vacuolar pH of Saccharomyces cerevisiae. BBA-Biomembranes. 1997;1325:63-70.

21. Ambesi A, Miranda M, Petrov WV, Slayman CW. Biogenesis and function of the yeast plasma-membrane H(+)-ATPase. J Exp Biol. 2000;203:155-60.

22. Morsomme P, Slayman CW, Goffeau A. Mutagenic study of the structure, function and biogenesis of the yeast plasma membrane $\mathrm{H}(+)$-ATPase. Biochim Bioph Acta. 2000;1469:133-57.

23. Fernandes AR, Mira NP, Vargas RC, Canelhas I, Sa-Correia I. Saccharomyces cerevisiae adaptation to weak acids involves the transcription factor Haa $1 \mathrm{p}$ and Haa1 p-regulated genes. Biochem Bioph Res Co. 2005;337:95-103.

24. Mira NP, Becker JD, Sá-Correia I. Genomic expression program involving the Haa1 1 -regulon in Saccharomyces cerevisiae response to acetic acid. OMICS. 2010;14:587-601.

25. Ahmad M, Hirz M, Pichler H, Schwab H. Protein expression in Pichia pastoris: recent achievements and perspectives for heterologous protein production. Appl Microbiol Biotechnol. 2014;2014(98):5301-17.

26. Cregg JM, Cereghino JL, Shi J, Higgins DR. Recombinant protein expression in Pichia pastoris. Mol Biotechnol. 2000;16:23-52.

27. Liu Y, Tu X, Xu Q, Bai C, Kong C, Liu Q, et al. Engineered monoculture and co-culture of methylotrophic yeast for de novo production of monacolin J and lovastatin from methanol. Metab Eng. 2018;45:189-99.

28. Kong C, Huang H, Xue Y, Liu Y, Peng Q, Liu Q, et al. Heterologous pathway assembly reveals molecular steps of fungal terreic acid biosynthesis. Sci Rep. 2018;8:2116.

29. Giannattasio S, Guaragnella N, Zdralevic M, Marra E. Molecular mechanisms of Saccharomyces cerevisiae stress adaptation and programmed cell death in response to acetic acid. Front Microbiol. 2013;4:33.

30. Goossens A, De LFN, Forment J, Serrano R, Portillo F. Regulation of yeast $\mathrm{H}(+)$-ATPase by protein kinases belonging to a family dedicated to activation of plasma membrane transporters. Mol Cell Biol. 2000;20:7654-61.

31. Shen W, Kong C, Xue Y, Liu Y, Cai M, Zhang Y, et al. Kinase screening in Pichia pastoris identified promising targets involved in cell growth and alcohol oxidase 1 promoter $\left(\mathrm{P}_{A O X_{1}}\right)$ regulation. PLOS ONE. 2016;11:e0167766.

32. Starai VJ, Gardner JG, Escalante-Semerena JC. Residue Leu-641 of acetylCoA synthetase is critical for the acetylation of residue Lys- 609 by the protein acetyltransferase enzyme of Salmonella enterica. J Biol Chem. 2005;280:26200-5.

33. De SK, Lin YC, Tiels P, Van HA, Glinka S, Weberlehmann J, et al. Genome sequence of the recombinant protein production host Pichia pastoris. Nat Biotechnol. 2009;27:561-6.

34. Ahmed K, Gerber DA, Cochet C. Joining the cell survival squad: an emerging role for protein kinase CK2. Trends Cell Biol. 2002;12:226-30.

35. Shero $\mathrm{JH}$, Hieter P. A suppressor of a centromere DNA mutation encodes a putative protein kinase (MCK1). Gen Dev. 1991;5:549-60.

36. Neigeborn L, Mitchell AP. The yeast MCK1 gene encodes a protein kinase homolog that activates early meiotic gene expression. Gen Dev. 1991;5:533-48.

37. Posas F, Wurgler-Murphy SM, Maeda T, Witten EA, Thai TC, Saito H. Yeast HOG1 MAP kinase cascade is regulated by a multistep phosphorelay mechanism in the SLN1-YPD1-SSK1 "two-component" osmosensor. Cell. 1996;86:865-75.

38. Gaur NA, Hasek J, Brickner DG, Qiu H, Zhang F, Wong CM, et al. Vps factors are required for efficient transcription elongation in budding yeast. Genetics. 2013;193:829-51.

39. Serrano R, Kiellandbrandt MC, Fink GR. Yeast plasma membrane ATPase is essential for growth and has homology with $\left(\mathrm{Na}^{+}+\mathrm{K}^{+}\right), \mathrm{K}^{+}$- and $\mathrm{Ca}^{2+}$-ATPases. Nature. 1986;319:689-93.

40. Mazón MJ, Eraso P, Portillo F. Specific phosphoantibodies reveal two phosphorylation sites in yeast Pma1 in response to glucose. FEMS Yeast Res. 2015;15:fav030.

41. Serrano R. Structure and function of proton translocating ATPase in plasma membranes of plants and fungi. Biochim Bioph Acta. 1988;947:1-28.

42. Lian J, Si T, Nair NU, Zhao H. Design and construction of acetyl-CoA overproducing Saccharomyces cerevisiae strains. Metab Eng. 2014;24:139-49. 
43. Lee Y, Nasution O, Lee YM, Kim E, Choi W, Kim W. Overexpression of PMA1 enhances tolerance to various types of stress and constitutively activates the SAPK pathways in Saccharomyces cerevisiae. Appl Microbiol Biotechnol. 2017;101:229-39.

44. Gao L, Cai M, Shen W, Xiao S, Zhou X, Zhang Y. Engineered fungal polyketide biosynthesis in Pichia pastoris: a potential excellent host for polyketide production. Microb Cell Fact. 2013;12:77.

45. Eraso P, Cid A, Serrano R. Tight control of the amount of yeast plasma membrane ATPase during changes in growth conditions and gene dosage. FEBS Lett. 1987;224:193.

46. Paiva S, Devaux F, Barbosa S, Jacq C, Casal M. Ady2p is essential for the acetate permease activity in the yeast Saccharomyces cerevisiae. Yeast. 2004:21:201-10
47. Pacheco A, Talaia G, Sápessoa J, Bessa D, Gonçalves MJ, Moreira R, et al. Lactic acid production in Saccharomyces cerevisiae is modulated by expression of the monocarboxylate transporters Jen 1 and Ady2. FEMS Yeast Res. 2012;12:375-81.

48. Huang M, Gao Y, Zhou X, Zhang Y, Cai M. Regulating unfolded protein response activator hac1p for production of thermostable rawstarch hydrolyzing a-amylase in Pichia pastoris. Bioproc Biosyst Eng. 2016;40:1-10

49. Brewster RC, Weinert FM, Garcia HG, Song D, Rydenfelt M, Phillips R. The transcription factor titration effect dictates level of gene expression. Cell. 2014;156:1312-23.
Ready to submit your research? Choose BMC and benefit from:

- fast, convenient online submission

- thorough peer review by experienced researchers in your field

- rapid publication on acceptance

- support for research data, including large and complex data types

- gold Open Access which fosters wider collaboration and increased citations

- maximum visibility for your research: over $100 \mathrm{M}$ website views per year

At BMC, research is always in progress.

Learn more biomedcentral.com/submissions 